\title{
Lung stereotactic body radiation therapy for elderly patients aged $\geq 80$ years with pathologically proven early-stage non-small cell lung cancer: a retrospective cohort study
}

Kenta Watanabe ${ }^{1}$, Kuniaki Katsui ${ }^{2 *}$ (D, Soichiro Sugiyama ${ }^{1}$, Kotaro Yoshio ${ }^{1}$, Masahiro Kuroda ${ }^{3}$, Takao Hiraki ${ }^{4}$, Katsuyuki Kiura ${ }^{5}$, Yoshinobu Maeda ${ }^{6}$, Shinichi Toyooka ${ }^{7}$ and Susumu Kanazawa ${ }^{4}$

\begin{abstract}
Background: Stereotactic body radiation therapy (SBRT) is an established therapy for medically inoperable earlystage non-small cell lung cancer (NSCLC). Many elderly patients are medically inoperable owing to comorbidities. Therefore, SBRT may be a useful therapy for elderly patients. However, the application of SBRT for patients aged $\geq 80$ years has not been completely elucidated. Therefore, this study aimed to assess the clinical utility of SBRT for elderly patients aged $\geq 80$ years with pathologically proven early-stage NSCLC.

Methods: We retrospectively evaluated the data of patients aged $\geq 80$ years with pathologically proven primary NSCLC who underwent SBRT at our institution between January 2009 and March 2020. Treatment outcomes and toxicities were analyzed. We used the Kaplan-Meier method to estimate survival curves and the log-rank test to compare the survival curves. We performed univariate and multivariate Cox regression analyses. $p$-values $<0.05$ were regarded significant.

Results: Sixty-four patients (65 lesions) were included, and the median follow-up period was 38.7 (range 3.5-95.7) months. The median age was 82.9 (range 80.0-94.8) years. Sixteen patients were medically operable, and 48 patients were medically inoperable. The prescribed dose of SBRT was either $48 \mathrm{~Gy}$ in four fractions or $60 \mathrm{~Gy}$ in 10 fractions. The median survival time was 60.0 months (95\% confidence interval, 43.5-71.1). The 1-, 3-, and 5-year local control, cancerspecific survival, progression-free survival, and overall survival rates were $98.4 \%, 98.4 \%, 81.0 \%$, and $88.9 \% ; 90.1 \%$, 93.7\%, 58.9\%, and 68.3\%; and 87.4\%, 83.5\%, 38.2\%, and 47.5\%, respectively. Multivariate analysis revealed that inoperability and solid nodules were the predictors of poor overall survival after SBRT in elderly patients. Two patients (3.1\%) had grade 3 radiation pneumonitis, and one patient (1.6\%) had grade 5 radiation pneumonitis.
\end{abstract}

Conclusions: SBRT was feasible in patients aged $\geq 80$ years with NSCLC. It achieved good local control with minimal toxicity. SBRT may be beneficial in elderly patients with early-stage NSCLC.

\footnotetext{
*Correspondence: kukatsui@cc.okayama-u.ac.jp

2 Department of Proton Beam Therapy, Okayama University Graduate

School of Medicine, Dentistry, and Pharmaceutical Sciences, 2-5-1

Shikata-cho, Kita-ku, Okayama 700-8558, Japan

Full list of author information is available at the end of the article
}

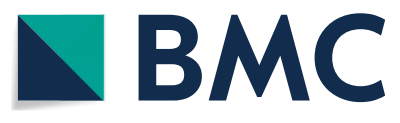

(c) The Author(s) 2021. Open Access This article is licensed under a Creative Commons Attribution 4.0 International License, which permits use, sharing, adaptation, distribution and reproduction in any medium or format, as long as you give appropriate credit to the original author(s) and the source, provide a link to the Creative Commons licence, and indicate if changes were made. The images or other third party material in this article are included in the article's Creative Commons licence, unless indicated otherwise in a credit line to the material. If material is not included in the article's Creative Commons licence and your intended use is not permitted by statutory regulation or exceeds the permitted use, you will need to obtain permission directly from the copyright holder. To view a copy of this licence, visit http://creativecommons.org/licenses/by/4.0/. The Creative Commons Public Domain Dedication waiver (http://creativeco mmons.org/publicdomain/zero/1.0/) applies to the data made available in this article, unless otherwise stated in a credit line to the data. 
Keywords: Clinical pathology, Elderly, Non-small cell lung carcinoma, Radiosurgery, Stereotactic body radiation therapy

\section{Background}

Primary lung cancer is one of the common life-threatening malignancies and is the main cause of death among all cancers [1]. The proportion of elderly patients with primary lung cancer is predicted to increase owing to the aging of the general population $[2,3]$. Therefore, the treatment strategy for elderly patients with primary lung cancer is an important consideration.

Surgery is the standard treatment for early-stage nonsmall cell lung cancer (NSCLC) [4]. However, no evidence-based standard treatments for elderly patients with NSCLC exist, particularly for those aged $\geq 80$ years. Although surgical resection is an effective treatment for elderly patients [5], it is often not feasible in elderly patients aged $\geq 80$ years owing to comorbidities.

Stereotactic body radiation therapy (SBRT) is the usual treatment for medically inoperable patients, and it provides good local control rates and induces minimal toxicity [6-11]. Therefore, SBRT may be beneficial in elderly patients. According to a national survey in South Korea, the percentage of patients aged $\geq 80$ years receiving SBRT as a treatment modality for early NSCLC increased from $9.4 \%$ in 2008 to $28.6 \%$ in 2016 [12]. While some studies have revealed that SBRT is an effective and safe treatment modality in elderly patients aged $\geq 80$ years [13-15], most studies included patients who were not pathologically confirmed to have NSCLC.

Pulmonary nodules may be benign (e.g., organized pneumonia, tuberculosis, and sclerosing hemangioma) $[16,17]$. Radiation therapy to treat these infectious nodules or benign lesions is contraindicated. Therefore, it is desirable to make a definitive diagnosis before cancer treatment. A study reported the outcomes of SBRT for patients aged $\geq 75$ years with pathologically proven early-stage NSCLC [18]. This study revealed that SBRT had excellent tumor control rates and low toxicity rates in patients aged $\geq 75$ years with proven NSCLC. However, to the best of our knowledge, with respect to the clinical outcome of SBRT, there is no study in which all patients aged $\geq 80$ years have been pathologically diagnosed to have NSCLC. Thus, this study aimed to assess the clinical utility of SBRT for elderly patients aged $\geq 80$ years with pathologically proven early-stage NSCLC.

\section{Methods}

\section{Patients}

We retrospectively evaluated the data of consecutive patients aged $\geq 80$ years at the start of SBRT for
T1-2N0M0 (tumor-node-metastasis classification, 8th edition) primary lung cancer at Okayama University Hospital between January 2009 and March 2020. Patients without pathologically proven NSCLC were excluded.

Computed tomography (CT) scan was performed for all patients to stage their lung cancer. On CT, the lesions were classified as ground-glass, part solid, or solid, and tumor size was measured including that of ground glass lesions. Positron emission tomography, if performed, was also used for cancer staging. All tumors were subjected to CT-guided or bronchoscope-guided biopsies to confirm the pathology. Data related to patients' pretreatment Eastern Cooperative Oncology Group (ECOG) performance status (PS) score and body mass index were collected. The Charlson Comorbidity Index was calculated. Global Initiative for Chronic Obstructive Lung Disease stage was classified according to the results of the pretreatment pulmonary function tests. Board-certified thoracic surgeons or respiratory physicians determined whether the patients could tolerate surgical resection after considering respiratory function, comorbidities, possibility of general anesthesia, and general condition. Patients who could not tolerate surgery were defined as medically inoperable.

\section{Treatment}

Long-scan-time non-breath-hold CT was performed to delineate the internal target volume after immobilization with the Vac-Loc and Hip-Fix systems (CIVCO Medical Solutions, Orange City, IA, USA), and compressing the chest and abdomen. The respiratory motion was reduced by using the aforementioned device and respiratory depression. We used X-ray fluoroscopy to evaluate tumor motion. The planning target volume (PTV) included the internal target volume plus a $5-8-\mathrm{mm}$ margin. A radiation therapy planning system (Xio version 4.8.0; Elekta, Stockholm, Sweden) was used with a superposition dose calculation algorithm with heterogeneity correction. Radiation therapy was delivered using 6-MV photons from a linear accelerator (Primus; Canon Medical Systems, Tochigi, Japan) in multiple coplanar and noncoplanar static ports. We prescribed 48 Gy in 4 fractions for peripheral lesions and 60 Gy in 10 fractions for central lesions or lesions adjacent to the brachial plexus. SBRT was performed daily on weekdays. Until October 31, 2015, the prescribed dose was defined as the dose at the isocenter. Subsequently, the prescribed dose was defined as the dose covering 95\% of the PTV (D95). We 
evaluated toxicities using the Common Terminology Criteria for Adverse Events (version 5.0) [19]. We collected the data on grade $\geq 3$ adverse events.

\section{Statistical analysis}

We estimated local control (LC), cancer-specific survival (CSS), progression-free survival (PFS), and overall survival (OS) rates using the Kaplan-Meier method and compared survival curves using the log-rank test. We performed univariate and multivariate Cox regression analyses to determine if either clinical or treatment-related factors could predict LC, CSS, PFS, or OS. Variables with $p$-values $<0.05$ in the univariate analysis were retained in the multivariate analysis. We used Stata/ IC 16.1 (StataCorp, College Station, TX, USA) to conduct statistical analyses. $p$-values $<0.05$ were considered statistically significant.

\section{Results}

\section{Patient characteristics}

In total, 162 consecutive patients (166 lesions) were treated with SBRT at our hospital between January 2009 and March 2020. Among those patients, 64 patients (65 lesions; 45 men and 19 women) aged $\geq 80$ years with pathologically proven NSCLC were included in our study. Sixty-three patients had been evaluated using positron emission tomography-CT before the treatment. The median (range) age and ECOG PS were 82.9 (80.0-94.8) years and $1(0-3)$, respectively. The median (range) follow-up period after SBRT was 38.7 (3.5-95.7) months. One patient had synchronous primary lung cancer. No patient had interstitial pneumonia before treatment. Patient and tumor characteristics are summarized in Table 1.

\section{Treatment and disease control}

The median survival time was 60.0 months (95\% confidence interval, 43.5-71.1). Forty-one patients were treated with 48 Gy to the isocenter, six were treated with $60 \mathrm{~Gy}$ to the isocenter, and 18 were treated with $48 \mathrm{~Gy}$ (D95). The median (range) PTV was 32.4 (9.6-110.6) $\mathrm{ml}$. The 1-, 3-, and 5-year LC rates were $98.4 \%, 90.1 \%$, and 87.4\%, respectively. The 1-, 3-, and 5-year CSS, PFS, and OS rates were $98.4 \%, 93.7 \%$, and $83.5 \% ; 81.0 \%, 58.9 \%$, and $38.2 \%$; and $88.9 \%, 68.3 \%$, and $47.5 \%$, respectively (Table 2 and Fig. 1). The median time to local recurrence among the patients who developed local recurrence was 25.3 months (95\% confidence interval, 7.7-38.1).

The OS rates for operable $(\mathrm{n}=16)$ and inoperable $(\mathrm{n}=48)$ patients are shown in Fig. 2. The 1-, 3-, and 5 -year OS rates for operable and inoperable patients were $100.0 \%, 79.4 \%$, and $79.4 \%$, and $85.4 \%, 64.7 \%$, and $36.6 \%$,
Table 1 Patient and tumor characteristics

\begin{tabular}{|c|c|}
\hline Characteristic & Value \\
\hline Age (years), median (range) & $83(80.0-94.8)$ \\
\hline Sex $(n)$, male/female & $45 / 19$ \\
\hline Follow-up (months), median (range) & $39(3.5-95.7)$ \\
\hline BMI $\left(\mathrm{kg} / \mathrm{m}^{2}\right)$, median (range) & $22.8(16.7-29.4)$ \\
\hline BMI distribution $(n),<18.5 / 18.5-25.0 />25 \mathrm{~kg} / \mathrm{m}^{2}$ & $5 / 48 / 11$ \\
\hline ECOG PS (n), 0/1/2/3 & 28/19/11/6 \\
\hline Operability (n), yes/no & $16 / 48$ \\
\hline GOLD stage $(\mathrm{n})$, normal/I/II/III & $24 / 18 / 13 / 4$ \\
\hline FEV1.0 (L), median (range) $\dagger$ & $1.6(0.7-2.7)$ \\
\hline History of lung operation (n), yes/no & $14 / 50$ \\
\hline Charlson Comorbidity Index (n), 2/3/4/5/6/7/9 & $10 / 28 / 12 / 7 / 3 / 2 / 2$ \\
\hline T stage (n), Tis/T1mi/T1a/T1b/T1c/T2a/T2b & $2 / 2 / 5 / 26 / 17 / 10 / 3$ \\
\hline Maximum tumor diameter (cm), median (range) & $2.1(0.8-4.1)$ \\
\hline ITV $(\mathrm{mL})$, median (range) & $10.2(1.1-51.8)$ \\
\hline PTV (mL), median (range) & $32.4(9.6-110.6)$ \\
\hline \multicolumn{2}{|l|}{ Histology (n) } \\
\hline Adenocarcinoma & 43 \\
\hline Squamous cell carcinoma & 19 \\
\hline Unclassified NSCLC & 3 \\
\hline Tumor opacity (n), pure GGN/part solid GGN/solid & $2 / 18 / 45$ \\
\hline Location (n), central/peripheral & $1 / 64$ \\
\hline Location (n), left/right & $24 / 41$ \\
\hline Location (n), upper lobe/middle lobe/lower lobe & $37 / 1 / 27$ \\
\hline \multicolumn{2}{|l|}{ Prescribed dose $(n)$} \\
\hline 48 Gy (isocenter) & 41 \\
\hline 60 Gy (isocenter) & 6 \\
\hline 48 Gy (D95) & 18 \\
\hline
\end{tabular}

BMI, body mass index; D95, dose covering 95\% of the PTV; ECOG, Eastern Cooperative Oncology Group; GOLD, Global Initiative for Chronic Obstructive Lung Disease; FEV, forced expiratory volume; GGN, ground-glass nodule; ITV, internal target volume; NSCLC, non-small cell lung cancer; PS, performance status; PTV, planning target volume

† These variables have missing values

Table 2 Local control and survival rates after stereotactic body radiation therapy

\begin{tabular}{llll}
\hline Parameter & 1-year & 3-year & 5-year \\
\hline Local control (\%) & 98.4 & 90.1 & 87.4 \\
Cancer-specific survival (\%) & 98.4 & 93.7 & 83.5 \\
Progression-free survival (\%) & 81.0 & 58.9 & 38.2 \\
Overall survival (\%) & 88.9 & 68.3 & 47.5 \\
\hline
\end{tabular}

respectively, with significant differences in the survival curves (log-rank test, $p=0.003$ ).

Univariate analysis did not identify any predictors of LC or CSS. However, univariate analysis did identify ECOG PS, operability, tumor appearance, and tumor histology as the predictors of PFS $[p=0.035,0.014,0.021$, 

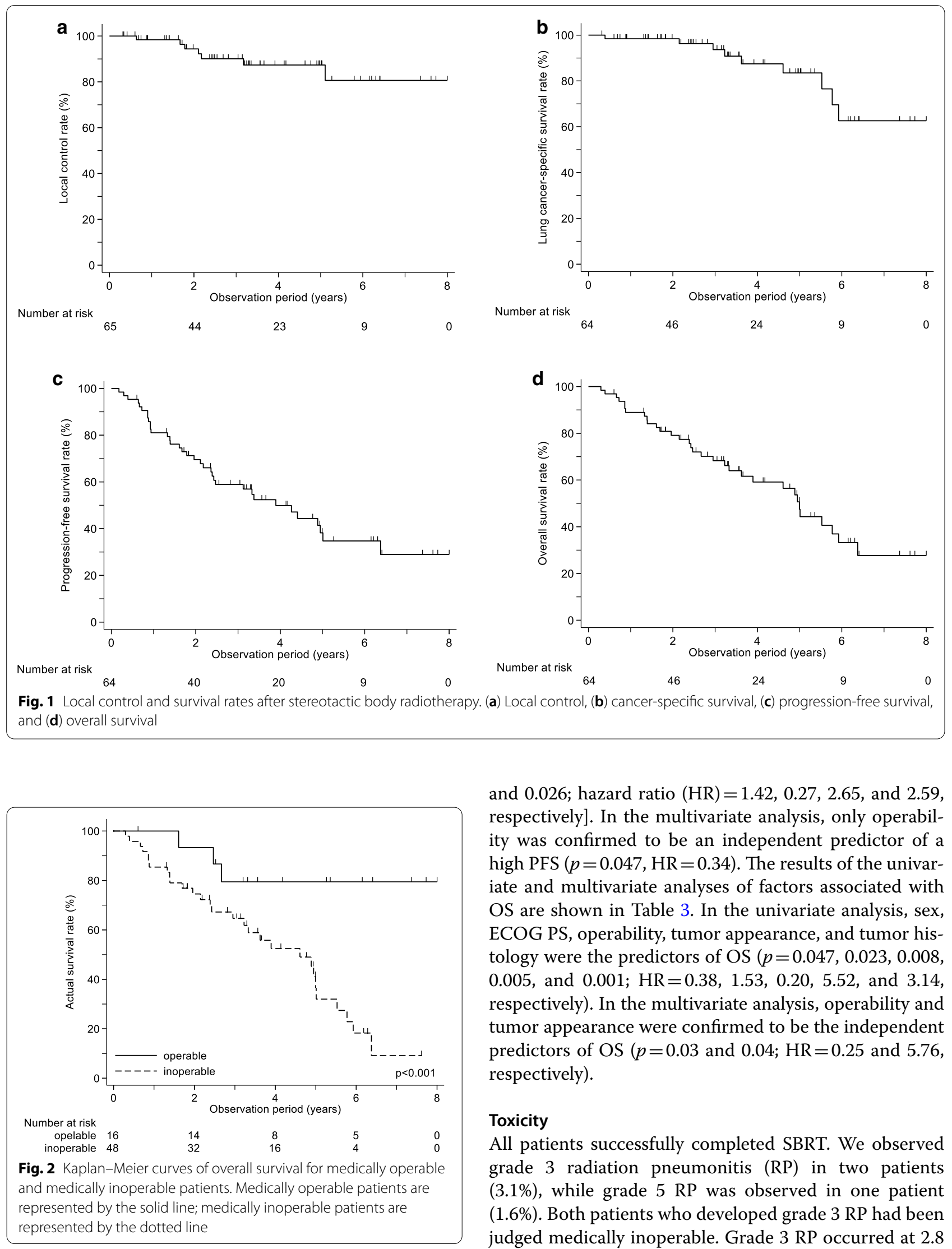

and 0.026; hazard ratio $(\mathrm{HR})=1.42,0.27,2.65$, and 2.59, respectively]. In the multivariate analysis, only operability was confirmed to be an independent predictor of a high PFS ( $p=0.047, \mathrm{HR}=0.34)$. The results of the univariate and multivariate analyses of factors associated with OS are shown in Table 3. In the univariate analysis, sex, ECOG PS, operability, tumor appearance, and tumor histology were the predictors of OS $(p=0.047,0.023,0.008$, 0.005 , and $0.001 ; \mathrm{HR}=0.38,1.53,0.20,5.52$, and 3.14 , respectively). In the multivariate analysis, operability and tumor appearance were confirmed to be the independent predictors of OS $(p=0.03$ and $0.04 ; \mathrm{HR}=0.25$ and 5.76, respectively).

\section{Toxicity}

All patients successfully completed SBRT. We observed grade 3 radiation pneumonitis (RP) in two patients (3.1\%), while grade $5 \mathrm{RP}$ was observed in one patient (1.6\%). Both patients who developed grade 3 RP had been judged medically inoperable. Grade 3 RP occurred at 2.8 
Table 3 Univariate and multivariate analyses of overall survival

\begin{tabular}{|c|c|c|c|c|c|c|c|}
\hline \multirow[t]{2}{*}{ Characteristic } & \multirow[t]{2}{*}{$\mathbf{n}$} & \multicolumn{3}{|c|}{ Univariate analysis } & \multicolumn{3}{|c|}{ Multivariate analysis } \\
\hline & & HR & $95 \% \mathrm{Cl}$ & $p$-value & HR & $95 \% \mathrm{Cl}$ & $p$-value \\
\hline Age (years) & - & 1.07 & $0.95-1.21$ & 0.24 & - & - & - \\
\hline \multicolumn{8}{|l|}{ Sex } \\
\hline Male & 45 & 1.00 & - & - & 1.00 & - & - \\
\hline Female & 19 & 0.38 & $0.15-0.99$ & $0.04^{*}$ & 1.85 & $0.48-7.18$ & 0.38 \\
\hline BMI $\left(\mathrm{kg} / \mathrm{m}^{2}\right)$ & - & 0.97 & $0.86-1.10$ & 0.65 & - & - & - \\
\hline ECOG PS & - & 1.53 & $1.06-2.21$ & $0.02^{*}$ & 1.26 & $0.84-1.89$ & 0.26 \\
\hline \multicolumn{8}{|l|}{ GOLD staget } \\
\hline Normal+I & 42 & 1.00 & - & - & - & - & - \\
\hline$\|+\|$ & 17 & 1.50 & $0.72-3.11$ & 0.28 & - & - & - \\
\hline FEV1.0 (L) † & & 0.46 & $0.20-1.06$ & 0.07 & - & - & - \\
\hline \multicolumn{8}{|l|}{ History of lung operation } \\
\hline No & 50 & 1.00 & - & - & - & - & - \\
\hline Yes & 14 & 1.49 & $0.68-3.24$ & 0.32 & - & - & - \\
\hline Charlson Comorbidity Index & - & 1.09 & $0.87-1.37$ & 0.45 & - & - & - \\
\hline \multicolumn{8}{|l|}{ Operable } \\
\hline No & 48 & 1.00 & - & - & 1.00 & - & - \\
\hline Yes & 16 & 0.20 & $0.06-0.66$ & $0.008^{* *}$ & 0.25 & $0.07-0.86$ & $0.03^{*}$ \\
\hline Tumor diameter (cm) & & 0.99 & $0.64-1.52$ & 0.96 & - & - & - \\
\hline ITV $(\mathrm{mL})$ & - & 1.00 & $0.97-1.03$ & 0.96 & - & - & - \\
\hline PTV $(m L)$ & - & 1.00 & $0.98-1.01$ & 0.83 & - & - & - \\
\hline Tstage & - & 1.16 & $0.88-1.53$ & 0.29 & - & - & - \\
\hline \multicolumn{8}{|l|}{ Histology } \\
\hline Adenocarcinoma & 43 & 1.00 & - & - & 1.00 & - & - \\
\hline $\mathrm{SCC}+\mathrm{NSCLC}$ & 22 & 3.14 & $1.56-6.31$ & $0.001^{* *}$ & 1.97 & $0.95-4.10$ & 0.07 \\
\hline \multicolumn{8}{|l|}{ Tumor appearance } \\
\hline Pure GGN + part-solid GGN & 20 & 1.00 & - & - & 1.00 & - & - \\
\hline Solid & 45 & 5.52 & $1.68-18.14$ & $0.005^{* *}$ & 5.76 & $1.05-31.71$ & $0.04^{*}$ \\
\hline \multicolumn{8}{|l|}{ Total dose (Gy) } \\
\hline 48 & 59 & 1.00 & - & - & - & - & - \\
\hline 60 & 6 & 0.94 & $0.83-1.06$ & 0.29 & - & - & - \\
\hline \multicolumn{8}{|l|}{ Prescribed dose } \\
\hline Isocenter & 47 & 1.00 & - & - & - & - & - \\
\hline D95 & 18 & 0.48 & $0.14-1.64$ & 0.24 & - & - & - \\
\hline
\end{tabular}

$p<0.05 ;{ }^{* *} p<0.01$

$\mathrm{BMI}$, body mass index; Cl, confidence interval; D95, dose covering 95\% of the PTV; ECOG, Eastern Cooperative Oncology Group; GGN, ground-glass nodule; GOLD, Global Initiative for Chronic Obstructive Lung Disease; FEV, forced expiratory volume; HR, hazard ratio; ITV, internal target volume; NSCLC, non-small cell lung cancer;

PS, performance status; PTV, planning target volume; SCC, squamous cell carcinoma

${ }^{\dagger}$ These variables have missing values

and 3.6 months after completing SBRT. The patient who developed grade 5 RP had been judged medically inoperable. SBRT was performed twice for bilateral lesions in the lower lobes. The patient died of respiratory failure 3.8 months after completing the second course of SBRT. The data pertaining to lung-related comorbidity, tumor location, and dosimetry of patients who developed grade $\geq 3 \mathrm{RP}$ are presented in Table 4. Except for $R P$, other grade $\geq 3$ adverse events such as rib fracture, esophageal stenosis, tracheobronchial stenosis, neuropathy, and hemorrhage were not reported.

\section{Discussion}

This study confirms that SBRT is associated with high LC rates, acceptable OS rates, and low toxicity rates in elderly patients aged $\geq 80$ years with pathologically proven NSCLC. 
Table 4 Lung-related comorbidity, tumor location, and dosimetric data of patients with radiation pneumonitis $\geq$ grade 3

\begin{tabular}{|c|c|c|c|}
\hline Patient number & 1 & 2 & 3 \\
\hline Adverse event and grade & RP grade 3 & RP grade 3 & RP grade 5 \\
\hline FEV1.0 (L) & 2.2 & 1.2 & 1.3 \\
\hline GOLD stage & 0 & 1 & 2 \\
\hline History of lung operation & No & No & No \\
\hline Tumor location & Right lower lobe & Right lower lobe & Bilateral lower lobe \\
\hline PTV $(m L)$ & 85.0 & 110.6 & $32.4 / 59.0$ \\
\hline Lung V20 (\%) & 8.4 & 16.2 & 18.3 \\
\hline MLD (Gy) & 6.0 & 8.8 & 10.9 \\
\hline
\end{tabular}

FEV, forced expiratory volume; GOLD, Global Initiative for Chronic Obstructive Lung Disease; MLD, mean lung dose; PTV, planning target volume; RP, radiation pneumonitis; V20, volume receiving at least $20 \mathrm{~Gy}$

Previous studies have shown that SBRT can achieve excellent therapeutic effects with only mild adverse events $[6-11,13,14,20]$. SBRT is less invasive than surgical resection and is performed for early-stage NSCLC in medically inoperable patients $[8,14]$. While surgery is the standard treatment for patients with early-stage NSCLC who can tolerate surgical resection [4], elderly patients aged $\geq 80$ years are often judged medically inoperable owing to comorbidities. Even when elderly patients are judged medically operable, surgical resection has been related to high morbidity and mortality rates [5, 20-22]. The postsurgical morbidity and mortality rates of elderly patients have been reported to be $18.0-45.0 \%$ and $0.0-$ $15.0 \%$, respectively $[21,23]$. Compared with surgical resection, SBRT is associated with a lower morbidity rate of $1.3-5.4 \%$ in elderly patients [23-25]. Furthermore, the frequency of grade 5 SBRT-related toxicities in elderly patients has been reported to be $0.0-2.1 \%[10,11,13,14]$. In the present study, two patients (3.1\%) developed grade $3 \mathrm{RP}$, and one patient developed grade $5 \mathrm{RP}$ (1.6\%). In the patient with grade $5 \mathrm{RP}$, non-breath-hold SBRT was performed twice for bilateral lesions in the lower lobes. Therefore, it is possible that the irradiated lung dose could have increased unexpectedly.

There are a few reports on the treatment outcomes of SBRT in elderly patients with pathologically proven NSCLC. Shu et al. [18] reported the outcomes of 68 patients aged $\geq 75$ years with pathologically proven early-stage (T1-3N0M0) NSCLC. The 1-, 3-, and 5-year LC rates were $95.6 \%, 88.9 \%$, and $85.6 \%$, respectively. The 1-, 3-, and 5-year OS rates were $92.6 \%, 77.2 \%$, and $59.1 \%$, respectively. In this study, the 1-, 3-, and 5-year LC and OS rates were $98.4 \%, 90.1 \%$, and $87.4 \%$, and $88.9 \%, 68.3 \%$, and $47.5 \%$, respectively. Although our OS rates may appear slightly worse, we postulate that these differences may be owing to the age of the patients because our LC rates were almost identical to those of the previous report [18]. Kreinbrink et al. [13], Takeda et al. [14], and Bei et al. [15] reported the treatment outcomes of elderly patients aged $\geq 80$ years with earlystage NSCLC. In the study by Kreinbrink et al. [13], the 1 - and 2-year LC and OS rates were $100.0 \%$ and $92.3 \%$, and $83.5 \%$ and $59.2 \%$, respectively. In the study by Takeda et al. [14], the 1- and 3-year LC and OS rates were $94.4 \%$ and $82.3 \%$, and $95.0 \%$ and $53.7 \%$, respectively. In the study by Bei et al. [15], the 3-year OS rate was $65.3 \%$ [15]. Our results are comparable to those of the previous three studies. However, the previous studies included some lesions that had not been pathologically confirmed as NSCLC. Pulmonary nodules can be benign as well as malignant $[16,17]$. Yang et al. reported the diagnostic accuracy of percutaneous transthoracic needle biopsy in the evaluation of solitary pulmonary nodules [16]. Among 311 nodules, 78 (25.1\%) nodules, including organized pneumonia, tuberculosis, sclerosing hemangioma, hamartoma, and aspergillosis, were benign. SBRT for benign lesions is contraindicated and, to some extent, can affect treatment outcomes. Because local recurrence and metastasis are not observed in a benign disease, LC and PFS may be higher than those in cases with pathologically diagnosed lung cancer. Therefore, it is desirable to make a definitive pathological diagnosis before cancer treatment. Because all SBRT-treated lesions in this study had been diagnosed as NSCLC, our treatment outcomes are more reliable. To the best of our knowledge, this is the first study to include only patients aged $\geq 80$ years with pathologically proven NSCLC.

There were no predictors of higher LC in this study. Previous studies showed that the biologically effective D95 was significantly correlated with the LC rate $[26,27]$. However, there was no significant difference between the prescribed doses (D95 vs. isocenter) in this study. The reason for this difference may be owing to the small sample size. Kimura et al. are conducting a nationwide clinical trial on dose escalation for SBRT 
[28]. This study is expected to reveal whether dose escalation is also beneficial in elderly patients.

In the present study, we found operability to be an independent predictor of good OS. Takeda et al. [14] reported that the 3-year OS rates for operable and inoperable patients were $58.1 \%$ and $48.3 \%$, respectively. Therefore, operability turned out to be a predictor of good OS after SBRT in elderly patients. Bei et al. [15] also demonstrated that operability was a predictor of good OS in multivariate analysis. Similarly, in our study, the 3-year OS rates for operable and inoperable patients were $79.4 \%$ and $64.7 \%$, respectively, and operability was a significant prognostic factor in multivariate analysis $(\mathrm{p}=0.03)$. Our results are comparable with those of the previous reports that have shown that medically operable patients have better prognosis. We initially considered that inoperable patients might have a shorter life expectancy than operable patients because inoperable patients had poor respiratory function, many comorbidities, or a poor general condition. Nagata et al. [8] reported that the 3-year OS rates for operable and inoperable patients in the Japan Clinical Oncology Group 0403 trial were 68.3\% and 63.7\%, respectively, and there is no difference in terms of OS between the two groups. In their study, less than onethird of the patients were aged $>81$ years, and the differences in patients' age may be the cause of these varying results. In elderly patients, operability may have a more pronounced effect on OS than in younger patients. However, further research is warranted.

Wang et al. showed that CT appearance was a significant prognostic factor for OS in patients with early-stage lung cancer who underwent surgery, with the worst prognosis for solid tumors [29]. Solid nodules were also a predictor of poor OS in our study. However, no reasonable interpretation of the OS data can be made because solid nodules were not a predictor of PFS in multivariate analysis. Since CT appearance is a significant prognostic factor for PFS in univariate analysis, this result may be owing to the small sample size of this study.

Our study has a few limitations. First, this was a retrospective, single-center study with a small sample size. Second, we did not use a quantitative model for judging operability. Instead, operability was judged based on the consensus of several thoracic surgeons or respiratory physicians. Nevertheless, the treatment outcomes showed that SBRT achieved high LC rates and acceptable OS rates, even in elderly patients aged $\geq 80$ years with pathologically proven NSCLC. In addition, our results indicated that medically operable patients had better treatment outcomes. We believe that our findings may help select an appropriate treatment strategy for patients aged $\geq 80$ years with NSCLC.

\section{Conclusions}

We reviewed treatment outcomes of SBRT for elderly patients aged $\geq 80$ years with pathologically proven NSCLC. Our findings suggest that SBRT is beneficial for elderly patients with early-stage NSCLC for whom it is difficult to determine the optimal treatment strategy.

\begin{abstract}
Abbreviations
Cl: Confidence interval; CSS: Cancer-specific survival; CT: Computed tomography; D95: Dose covering 95\% of the PTV; ECOG: Eastern Cooperative Oncology Group; FEV: Forced expiratory volume; GGN: Ground-glass nodule; GOLD: Global Initiative for Chronic Obstructive Lung Disease; HR: Hazard ratio; ITV: Internal target volume; LC: Local control; NSCLC: Non-small cell lung cancer; OS: Overall survival; PS: Performance status; PFS: Progression-free survival; PTV: Planning target volume; RP: Radiation pneumonitis; SBRT: Stereotactic body radiation therapy.
\end{abstract}

\section{Acknowledgements}

We wish to thank all the patients who participated in this study for their sincere cooperation. We also wish to thank Editage (www.editage.com) for English language editing.

\section{Author contributions}

All authors participated in the design of the study and have read and approved the final manuscript. KW collected the data, performed the statistical analysis, and drafted the manuscript. K. Katsui supervised the research. All authors read and approved the final manuscript.

\section{Funding}

This study was supported by a donation from Tsuyama Chuo Hospital. The funding body had no role in the design of the study and collection, analysis, and interpretation of data and in writing the manuscript.

\section{Availability of data and materials}

The datasets generated and/or analyzed during the current study are not publicly available due to the requirements of the Institutional Review Board, but are available from the corresponding author on reasonable request.

\section{Ethics approval and consent to participate}

This study was approved by the Institutional Review Board of Okayama University Graduate School of Medicine, Dentistry, and Pharmaceutical Sciences and Okayama University Hospital (approval number: 2005-011). Research was conducted in accordance with the principles of Declaration of Helsinki. Patients provided written informed consent for undergoing treatment and were provided the option to opt-out of this study via notifications displayed in the outpatient ward and on the institution's website.

\section{Consent for publication}

Not applicable.

\section{Competing interests}

K. Katsui belongs to the endowed course funded by Tsuyama Chuo Hospital. The other authors declare that they have no competing interests.

\section{Author details}

${ }^{1}$ Department of Radiology, Okayama University Hospital, 2-5-1 Shikata-cho, Kita-ku, Okayama 700-8558, Japan. ${ }^{2}$ Department of Proton Beam Therapy, Okayama University Graduate School of Medicine, Dentistry, and Pharmaceutical Sciences, 2-5-1 Shikata-cho, Kita-ku, Okayama 700-8558, Japan. ${ }^{3}$ Department of Radiological Technology, Graduate School of Health Sciences, Okayama University, 2-5-1 Shikata-cho, Kita-ku, Okayama 700-8558, Japan. ${ }^{4}$ Department of Radiology, Okayama University Graduate School of Medicine, Dentistry, and Pharmaceutical Sciences, 2-5-1 Shikata-cho, Kita-ku, Okayama 700-8558, Japan. ${ }^{5}$ Department of Allergy and Respiratory Medicine, Okayama University Hospital, 2-5-1 Shikata-cho, Kita-ku, Okayama 700-8558, Japan. ${ }^{6}$ Department of Hematology, Oncology, and Respiratory Medicine, Okayama University Graduate School of Medicine, Dentistry, 
and Pharmaceutical Sciences, 2-5-1 Shikata-cho, Kita-ku, Okayama 700-8558, Japan. ${ }^{7}$ Department of General Thoracic Surgery and Breast and Endocrinological Surgery, Okayama University Graduate School of Medicine, Dentistry, and Pharmaceutical Sciences, 2-5-1 Shikata-cho, Kita-ku, Okayama 700-8558, Japan.

Received: 12 December 2020 Accepted: 11 February 2021 Published online: 23 February 2021

\section{References}

1. Siegel RL, Miller KD, Jemal AJ. Cancer statistics, 2020. CA Cancer J Clin. 2020;70:7-30

2. Smith BD, Smith GL, Hurria A, Hortobagyi GN, Buchholz TA. Future of cancer incidence in the United States: burdens upon an aging, changing nation. J Clin Oncol. 2009;27:2758-65.

3. Spaggiari L, Scanagatta P. Surgery of non-small cell lung cancer in the elderly. Curr Opin Oncol. 2007;19:84-91.

4. Crinò L, Weder W, van Meerbeeck J, Felip E, ESMO Guidelines Working Group. Early stage and locally advanced (non-metastatic) non-small-cel lung cancer: ESMO Clinical Practice Guidelines for diagnosis, treatment and follow-up. Ann Oncol. 2010;21(Suppl. 5):103-15.

5. Rivera C, Falcoz PE, Bernard A, Thomas PA, Dahan M. Surgical management and outcomes of elderly patients with early stage non-small cell lung cancer: a nested case-control study. Chest. 2011;140:874-80.

6. Zheng X, Schipper M, Kidwell K, Lin J, Reddy R, Ren Y, et al. Survival outcome after stereotactic body radiation therapy and surgery for stage I non-small cell lung cancer: a meta-analysis. Int J Radiat Oncol Biol Phys. 2014;90:603-11.

7. Ma L, Xiang J. Clinical outcomes of video-assisted thoracic surgery and stereotactic body radiation therapy for early-stage non-small cell lung cancer: a meta-analysis. Thorac Cancer. 2016;7:442-51.

8. Nagata Y, Hiraoka M, Shibata T, Onishi H, Kokubo M, Karasawa K, et al. Prospective trial of stereotactic body radiation therapy for both operable and inoperable T1N0M0 non-small cell lung cancer: Japan Clinical Oncology Group Study JCOG0403. Int J Radiat Oncol Biol Phys. 2015;93:989-96.

9. Chi A, Liao Z, Nguyen NP, Xu J, Stea B, Komaki R. Systemic review of the patterns of failure following stereotactic body radiation therapy in earlystage non-small-cell lung cancer: clinical implications. Radiother Oncol. 2010;94:1-11.

10. Dong B, Wang J, Zhu X, Chen Y, Xu Y, Shao K, et al. Comparison of the outcomes of stereotactic body radiotherapy versus surgical treatment for elderly ( $\geq 70$ ) patients with early-stage non-small cell lung cancer after propensity score matching. Radiat Oncol. 2019;14:195.

11. Brooks ED, Sun B, Zhao L, Komaki R, Liao Z, Jeter M, et al. Stereotactic ablative radiation therapy is highly safe and effective for elderly patients with early-stage non-small cell lung cancer. Int J Radiat Oncol Biol Phys. 2017;98:900-7.

12. Lee K, Kim HO, Choi HK, Seo GH. Real-world treatment patterns for patients 80 years and older with early lung cancer: a nationwide claims study. BMC Pulm Med. 2018;18:127.

13. Kreinbrink P, Blumenfeld P, Tolekidis G, Sen N, Sher D, Marwaha G. Lung stereotactic body radiation therapy (SBRT) for early-stage non-small cell lung cancer in the very elderly ( $\geq 80$ years old): extremely safe and effective. J Geriatr Oncol. 2017:8:351-5.

14. Takeda A, Sanuki N, Eriguchi T, Kaneko T, Morita S, Handa H, et al. Stereotactic ablative body radiation therapy for octogenarians with non-small cell lung cancer. Int J Radiat Oncol Biol Phys. 2013;86:257-63.

15. Bei Y, Murakami N, Nakayama Y, Okuma K, Kashihara T, Raturi VP, et al. Stereotactic body radiation therapy for early-stage non-small-cell lung cancer in octogenarians and older: an alternative treatment. J Radiat Res. 2020;61:586-93.

16. Yang W, Sun W, Li Q, Yao Y, Lv T, Zeng J, et al. Diagnostic accuracy of CTguided transthoracic needle biopsy for solitary pulmonary nodules. PLoS ONE. 2015;10:e0131373.

17. Choi JW, Park CM, Goo JM, Park YK, Sung W, Lee HJ, et al. C-arm conebeam CT-guided percutaneous transthoracic needle biopsy of small ( $\leq$ $20 \mathrm{~mm}$ ) lung nodules: diagnostic accuracy and complications in 161 patients. AJR Am J Roentgenol. 2012;199:W322-30.

18. Shu Z, Dong B, Shi L, Shen W, Hang Q, Wang J, et al. Stereotactic body radiotherapy for elderly patients ( $\geq 75$ years) with early-stage non-small cell lung cancer. J Cancer Res Clin Oncol. 2020;146:1263-71.

19. US Department of Health and Human Services, National Institutes of Health, National Cancer Institute (2017) Common terminology criteria for adverse events (CTCAE) v5.0 https://ctep.cancer.gov/protocolDevelop ment/electronic_applications/ctc.htm\#ctc_50.

20. Nagata Y, Hiraoka M, Mizowaki T, Narita Y, Matsuo Y, Norihisa Y, et al. Survey of stereotactic body radiation therapy in Japan by the Japan 3-D Conformal External Beam Radiotherapy Group. Int J Radiat Oncol Biol Phys. 2009:75:343-7.

21. Berry MF, Onaitis MW, Tong BC, Harpole DH, D'Amico TA. A model for morbidity after lung resection in octogenarians. Eur J Cardiothorac Surg. 2011;39:989-94.

22. Jaklitsch MT, Bueno R, Swanson SJ, Mentzer SJ, Lukanich JM, Sugarbaker DJ. New surgical options for elderly lung patients. Chest. 1999;116:480S-S485.

23. Crabtree TD, Denlinger CE, Meyers BF, El Naqa I, Zoole J, Krupnick AS, et al. Stereotactic body radiation therapy versus surgical resection for stage I non-small cell lung cancer. J Thorac Cardiovasc Surg. 2010;140:377-86.

24. Onishi H, Shirato H, Nagata Y, Hiraoka M, Fujino M, Gomi K, et al. Hypofractionated stereotactic radiotherapy (HypoFXSRT) for stage I non-small cell lung cancer: updated results of 257 patients in a Japanese multiinstitutional study. J Thorac Oncol. 2007;2(7 Suppl. 3):S94-100.

25. Timmerman R, Papiez L, McGarry R, Likes L, DesRosiers C, Frost S, et al. Extracranial stereotactic radioablation: results of a phase I study in medically inoperable stage I non-small cell lung cancer. Chest. 2003; 124:1946-55.

26. Zhao L, Zhou S, Balter P, Shen C, Gomez DR, Welsh JD, et al. Planning target volume D95 and mean dose should be considered for optimal local control for stereotactic ablative radiation therapy. Int J Radiat Oncol Biol Phys. 2016;95:1226-35.

27. Thibault I, Poon I, Yeung L, Erler D, Kim A, Keller B, et al. Predictive factors for local control in primary and metastatic lung tumours after four to five fraction stereotactic ablative body radiotherapy: a single institution's comprehensive experience. Clin Oncol (R Coll Radiol). 2014;26:713-9.

28. Kimura T, Nagata Y, Eba J, Ozawa S, Ishikura S, Shibata T, et al. A randomized phase III trial of comparing two dose-fractionations stereotactic body radiotherapy (SBRT) for medically inoperable Stage IA non-small cell lung cancer or small lung lesions clinically diagnosed as primary lung cancer: Japan Clinical Oncology Group Study JCOG1408 (J-SBRT trial). Jpn J Clin Oncol. 2017:47:277-81.

29. Wang C, Wu Y, Li J, Ren P, Gou Y, Shao J, et al. Distinct clinicopathologic factors and prognosis based on the presence of ground-glass opacity components in patients with resected stage I non-small cell lung cancer. Ann Transl Med. 2020:8:1133.

\section{Publisher's Note}

Springer Nature remains neutral with regard to jurisdictional claims in published maps and institutional affiliations. 